\title{
INTERVIEW
}

\section{An Interview with Mike Heyworth, Director of the Council for British Archaeology}

\author{
Conducted $4^{\text {th }}$ August 2004 by Julie Eklund and Peter Popkin (transcribed \\ and edited by Peter Popkin)
}

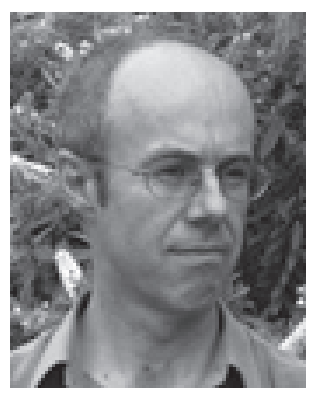

\begin{abstract}
Mike Heyworth was recently promoted to the position of Director of the Council for British Archaeology (CBA). He began his archaeology career as an undergraduate at Sheffield University and then studied for an MA in Scientific Methods and Archaeology at Bradford University. He continued his education at Bradford University pursuing a $\mathrm{PhD}$ part-time based on the use of inductively coupled plasma spectrometry to study early medieval glass. In 1987 he moved to London and began working in the Ancient Technology section of the English Heritage Ancient Monuments Laboratory studying a range of archaeological materials. He received his $\mathrm{PhD}$ from Bradford University in 1992. Since joining the CBA in 1990 as their Senior Bibliographer, he has held the posts of Information Officer and, more recently, Deputy Director.
\end{abstract}

\section{What first drew you to the CBA?}

The CBA in the early 1990s was a rather different organisation to what it is now. For example, it didn't have individual membership; that was introduced in 1993. Its key role really was one that bridged the whole sector, and that's still one of its key assets. It doesn't have any particular period or geographical interest. It covers the whole of the UK - all the time dimensions. My specific starting point, in a sense, was the archaeological science committee. The CBA had a whole range of specialist advisory committees, and they had one in archaeological science, so I got slightly involved with that because of my work in English Heritage. Increasingly, I began to appreciate that it was a critical organisation that underpinned a lot of what we do in archaeology in the UK. I thought that's the sort of organisation I'd like to be involved with, and fortunately enough it worked out.

How do you envision your role within the CBA will change now that you have become Director? And what are the primary goals you hope to accomplish during your directorship?

Up until now, primarily as Deputy Director, I've been particularly responsible for the operational management side of the CBA. Now, as Director, I'm much more responsible for the strategic management: setting the policy agenda and then trying to ensure that it is carried through by working with the staff, volunteers, regional groups and organisational and individual members. I've become Director at a very good time, I think, because our trustees over the last few years have been increasingly focusing on where they see the strategic direction of the CBA. In the last few months they've done quite a bit of thinking about the next five-year strategy period because we're just coming to the end of our current period, so we're starting to look from 2006 onwards. I've been able to contribute to the setting of that new strategy because I was involved on the inside already, and now I've effectively been given the task of implementing it. 
Broadly speaking, there are three key areas where we see the CBA's role in the next five to ten years: advocacy and campaigning, public participation and support services of various kinds. Those are the three umbrellas, but a lot of what we do in tangible terms maps across all of those three areas. One of the key things about the CBA is the interconnectedness of what we do internally, which hopefully is reflected externally in a more joined-up approach to the whole historic environment. Again, it means that, because we work across the UK, because we are working in the buildings side of archaeology as well as the buried side of archaeology, it means that we can see things and make connections that perhaps other organisations and people don't see. We are very well placed at the centre of a broad hub.

The CBA is an independent, non-profit making, educational charity which promotes conservation and appreciation of the past. Do you ever find that by working so closely with governmental bodies and policy makers it is difficult to remain truly independent?

No. It's an issue that is more about perception than reality, I think. There are one or two organisations that like to promote themselves as the only 'true' independent organisation in British archaeology, but I find that slightly ungenerous to other bodies. Yes, the CBA gets significant grant-in-aid on an annual basis from the British Academy, and we're supported by a number of national heritage agencies, but we've never been afraid to criticise anyone when we think they've done something that we don't agree with. But equally, on the other side, we're always very supportive when we think we should be. Our management structure, with an independent set of 15 trustees, ensures that we take a very broad strategic approach without being for or against a particular body. That's not our approach - we look at things on the basis of issues.

What do you think about the recent [2003] All Party Parliamentary Archaeology Group's (APPAG) call for the CBA, the Institute of Field Archaeologists (IFA) and the Institute of Historic Building Conservation (IHBC) to clarify and perhaps merge their respective functions in order to develop a single non-governmental organisation to act as a lobby for archaeology?

The introduction of APPAG is a really important initiative for archaeology, one that we really need to make the most of. Their report was extremely valuable to us and something that perhaps we all should be taking more note of than we are. A lot of their recommendations were extremely sound, and in fact, even just over a year on, many of their recommendations are already coming forward and either have happened or are being proposed to happen - so clearly it was an influential report.

Regarding the particular recommendation about the merger of the heritage bodies, I think that stemmed from a common recognition of the fact that as a sector we don't have a very good reputation for speaking with one voice. We have a reputation for being very divided amongst ourselves. Understandably, politicians aren't very keen to act on the basis of a divided view. What they want is a consensus view which they know will get broad support - something that they take up in policy terms and move forward with. So we need to get better at speaking with one voice where that's appropriate. 
There are a lot of good examples where we've done that, and where it has led to really solid achievements. I think the one that we all would point to is the area of portable antiquities, where for many years there has been support right across the sector for the change in the treasure trove legislation and then more recently for things like the introduction of the Portable Antiquities Scheme. The CBA was instrumental in bringing that sort of coalition together through what we call the Standing Conference on Portable Antiquities, which is a body that effectively operates under the aegis of the CBA. It is a coalition of all the key archaeological bodies. Over the ten years that they have been in operation, they've had regular meetings and come out with quite decisive statements which have been promulgated through government and have often led to solid action. So the case is well made for speaking with one voice.

On the particular bodies mentioned in the APPAG report, I think they were slightly misguided as to the specific nature of the organisations that they were talking about. The IFA and IHBC are both professional bodies, and there probably is a case for them working much more closely together and possibly merging in due course because they have similar functions. The CBA doesn't have similar functions; we're not a professional body. We're a much broader body, and I think APPAG themselves would now recognise that it wouldn't be appropriate for the CBA to merge with the IFA and the IHBC. Having said that, we do all need to work much more closely together, and we are doing that now in a number of different ways.

There are now two organisations which I think are quite important developments in the last few years, where this is starting to happen. One is Heritage Link, a body that bridges the whole of the historic environment sector, initially with underpinning support from the National Trust and English Heritage. It has a very broad-based membership of voluntary sector organisations and is working on behalf of its members to liaise with government and encourage the sector to work together better. That is a very important development. It's still a relatively young initiative, but it's gathering pace, I think. The other is what is called the Historic Environment Forum, a looser coalition of archaeological bodies including the CBA. It was set up in 1998 and has focused its attention on lobbying and working with government and politicians and has held a couple of open meetings. For example, we had a pre-election hustings meeting where we invited key politicians from the main parties to come along and talk about their view on archaeology and the historic environment. That was quite valuable. Currently we are also having a series of behind the scenes meetings with some of the politicians, mostly to try to persuade them about the value of archaeology and the historic environment - why they should effectively support it and put funds into it. So again, those two initiatives come out of the recognition that we need to speak with one voice and communicate more effectively with politicians. But I don't think it is actually best done by merging all of the bodies together because we all have different perspectives, we're all coming from different angles, and sometimes that can be very important.

As the European Union's legislative powers grow, do you envision European legislation affecting practice within British archaeology or vice versa? Well, obviously the key issue that has emerged to date is the Valetta Convention, which 
is a relatively old piece of 'legislation' on a European level [1992 - ed.] that was only relatively recently ratified by the UK [September 2000 - ed.] and really has had minimal impact. Although it created a great deal of fuss at the time, actually it was, broadly speaking, an updated version of a much earlier convention [European Convention for the Protection of Archaeological Heritage, 1969 - ed.], which the UK ratified a long time ago. There wasn't a great deal in it that was really new. At the time, a great deal of uncertainty was created by the part that seemed to suggest, if you wanted to read it in a certain way, that amateur archaeology would be phased out. It seemed to suggest that only people who were 'qualified' archaeologists would be allowed to operate. I think it was an unfortunate use of the word 'qualified'. The CBA argued that 'competent' would have been a more appropriate word to have used. One of the issues about working with European legislation is the translation between the different languages, where sometimes there isn't an exact equivalent in another language, so sometimes things get subtly distorted. Certainly, the use of the word 'competent' would have been more appropriate for Valetta. The government, quite helpfully I think, made a clear statement that it didn't see ratifying the Valetta Convention as the end of amateur archaeology. There is now work on a statement of principles that supports and underpins archaeological work generally - not in a prescriptive way, but setting out the key, core and ethics standards - which hopefully everybody can sign up to. That is important in a subject like ours, where we are destroying the resource that we rely on as we go along.

What would have a much bigger impact is if we got a European directive that was effectively equivalent to the one that we have for the natural environment, for habitats. We need to work with European archaeological colleagues to try to articulate why the historic environment is deserving of international support at a European scale, particularly through the protection regimes that exist. At the moment, the natural environment lobby is considerably strengthened in this country by being able to refer back to European legislation. We don't have that for the historic environment, and that is something which is one of our bigger objectives for the next few years.

Does the CBA currently collaborate with similar European, or other international archaeological institutions or is it strictly focused on the UK?

Our constitution says that we work on the archaeology of the UK or archaeology pertaining to the UK. We interpret that fairly broadly, and we have played quite a significant role in a number of European initiatives over the years. The key body that we've been linked with, partly because one of our previous directors helped set it up, is called the European Forum of Heritage Associations (FORUM). FORUM is, broadly, made up of voluntary sector groups across Europe although, of course, the concept of voluntary sector groups across Europe differs. In some parts of Europe, amateur archaeology isn't allowed. In Greece, for example, there is no voluntary sector; volunteers are not allowed to participate in heritage activities. But in the northwestern European countries there is more of a shared philosophy. The idea behind FORUM has partly been to try to enable the different voluntary agencies in the different countries to talk together and learn from shared experience and also to try to encourage exchanges between volunteers. One of the biggest initiatives they've undertaken is a series of summer camps 
throughout Europe which are open to other members of FORUM organisations. We've participated in that to a certain extent, although CBA is slightly different from other voluntary organisations in that we ourselves don't do fieldwork. Many other voluntary associations in Europe have their own fieldwork projects. What we've done in the UK is put them in touch with people who run fieldwork projects and made sure that there are bilateral arrangements. So FORUM is the key group that we've been involved with.

I'm also a member of the European Association of Archaeologists, which is effectively the professional association, and that is an increasingly influential and important body. It is now the key contact with the Council of Europe, which is the cultural forum within the European Parliament system and is a good route through which to talk to politicians. There has been recognition over the last few years that working at a European scale is to our advantage, and we are starting to put the mechanisms in place now to achieve that more effectively. At the same time, there has obviously been a huge number of specific, European archaeological projects through things like the Leonardo funds. I think that is all very helpful, particularly in our common labour market where archaeologists can now work anywhere in Europe.

One of the issues that comes out of that is the need to develop common skills initiatives and training initiatives so that people are familiar with the different ways of working across Europe. There has been an interesting project going on in a place called Mont Bouvray, in France, in the last year or so, run through the UK's Institute of Field Archaeologists. They were taking people from a number of different countries and training them to be trainers of people coming and working on excavation projects; so training the trainers. One of the great advantages of that project was that it didn't just train them how to do the training, on how to pass on the skills, but also involved sharing experiences of what the skills were in different countries, because obviously different countries have different traditions and different perspectives. There are a number of projects like that which are starting to come through where archaeology is quite well placed to take advantage of the sorts of initiatives that Europe is promoting. Archaeology doesn't stop at national boundaries, and therefore we have a much more international perspective, perhaps, than some other disciplines, and we can take advantage of that.

BSc and MSc degrees are increasingly being awarded at a variety of archaeology departments in place of the traditional BA and MA degrees. Do you think this is beneficial to graduates preparing to enter the workforce? I think there are a number of issues there. I think it is very good that archaeology degrees have become more interdisciplinary, because that reflects what archaeology is all about. It then enables people to specialise within that environment. Now understandably some people will want to take a more traditional arts-based approach; some people will want to take a more scientific approach. I did my Master's at Bradford which was at the time part of the Physics department, and they were, and still are, a department of archaeological sciences - very explicitly on the science side. That has pros and cons. 
A lot of students these days are actually reluctant to do science courses because they are considered to be harder than arts courses. And so by promoting ourselves as a science-based subject, we are not necessarily doing ourselves any favours in terms of the number of people we are attracting to study archaeology. It's quite interesting if you look at the application figures for arts versus science courses; the general feeling is that the science courses are more difficult, and therefore that student numbers are lower than they should be. But it's quite clear that archaeology does involve sciences, and it is important to bring them in and develop the skills and give people an appreciation of the techniques that they have to offer. Whether, at the end of the day, somebody going into archaeology as a career is better off having a BA arts-based course or a BSc sciencebased course - I'm not sure there is any difference, really. Archaeology is currently pretty much a graduate-based subject, most people have to go on from a BA to do a Master's, if not a doctoral degree, to gain some sort of specialist knowledge, which then makes them more employable in archaeology. So in a sense, I don't think that the route they come in at the undergraduate level matters too greatly.

There seem to be more and more specialist degrees available every year. Do you think this fragments the discipline, or is it a necessary development in order to address the wide range of material that archaeology covers?

I think it does fragment the discipline, and I think one of the big issues nowadays is how we bring people back together. I think that is a key role of the CBA - working with other partner organisations. There needs to be a better appreciation between the different parts of the archaeological sector of what their individual contributions are. I think one of the reasons why Masters' degrees have grown so diverse is because of the lack of other training and skills development opportunities available within the archaeology sector.

One of the things the CBA has been working hard on over the last few years is the development of a training agenda for professional and amateur archaeologists. We are part of a group called the Archaeology Training Forum, which was set up by English Heritage back in the late 1990s. One of the key things that has come out of that over the last few years is the need for continuing professional development and training once people are in the profession. Over the last year there has been the development of a set of what are called National Occupational Standards for archaeology. Although most people don't know about them yet, and they are not very widely applied, they are really important because they underpin how government would think about vocational subjects and about skills. Effectively, they are a description of the wide range of skills that are involved in archaeology, and what we need to do now is start to use them to enable people to get a better understanding of their own personal development - where their skills gaps are - and then we need to develop a better range of training options.

The key to all of this, inevitably, is flexibility. The Masters' courses are one route to gain some of these skills, but they aren't necessarily the only route. People are starting to look at opportunities for Modern Apprenticeships where people can go in with the basic knowledge and understanding from their academic background and work with 
people in a mentoring-type role. They actually do things in practice and develop the skills that way, rather than forcing students to do yet another post-graduate degree, with all of the expense that entails, which isn't necessarily helping to make somebody more employable.

One of the things that the employers in archaeology say, is that graduates applying for jobs often need to be re-trained. They don't have the work skills that the employers are looking for. That is a very general statement, and inevitably it varies in different places, but archaeology is very specialised now. Very few people now have the opportunity to be 'an archaeologist' in a sense. Most people are zooarchaeologists or maritime archaeologists or whatever, and that means that they have to develop some specialist skills and understand different techniques. At the moment, one of the few ways they can do that is through Masters' courses.

\section{Can you tell us about the archaeological consortium that is under develop- ment by the CBA and Society of Antiquaries of London to encourage the electronic publishing of archaeological journals?}

Sure. One of the things that has been very noticeable over the last few years is that the sciences have gone down the computer technology route much more rapidly than the humanities subjects. If you take subjects like astronomy, there are no longer any significant print journals in astronomy; they are all electronic - electronic only. They don't have a print equivalent for a number of reasons: partly because of ease of access and widespread application, but also institutional issues to do with library space and those sorts of very basic issues. I think we all recognise that archaeologists need to take advantage of the technology opportunities that exist to position ourselves so that we're not left behind in the revolution that is underway. Having said that, most archaeological publishers are not in a position to do that themselves. Most archaeological publishers are relatively small societies that rely on membership and often don't have staff but are voluntarily run, and therefore, our sector needs some organisations to support a consortium-based approach to take these things forward. Because it is an issue that the CBA has been focused on for quite some time, we decided to take a lead in this, together with the Society of Antiquaries of London through their director, Professor Martin Millet. We held an open meeting a year and a half ago to see if there was general interest in the sort of thing we were talking about. What we're broadly talking about is taking electronic versions of the current print journals - not replacing the print journals, not phasing out the print journals at this stage - but just taking electronic versions, which everybody creates as part of the printing process, so it is not something that is particularly new or revolutionary from that point of view, and then trying to make those electronic versions available through a web server to a broader audience. The hope is that it will broaden use of that material and also bring in new revenue which will then support those societies and enable them to develop further services for their members and for the sector.

At that initial meeting, which was well attended by about 70 individuals, there was very broad support for this sort of approach. In the intervening period, we've had another 
public meeting, and there has been quite a bit of work going on behind the scenes to set up a proposal whereby the CBA will be the body that undertakes the work and acts as the legal 'owner' of the consortium. What we're aiming to do is to get this all up and running by the $1^{\text {st }}$ January 2006 . We hope that by then we'll have as many journals and possibly monographs series as we can within the consortium's offerings.

The idea is that there will be a variety of ways in which people can access this material. They can either buy access to particular articles on a pay-per-article basis at a relatively low fee; they can subscribe to a particular journal on-line; or - and this is where the advantage to our approach becomes particularly strong - they can subscribe to the entire bundle of journals. One of the hopes is that by putting together a bundle, which incorporates major, possibly international, certainly national, regional and local journals, we can help the local journals and the local societies to reach audiences that they would never otherwise reach because they will be part of a bigger group. By taking this approach and doing it ourselves, it also means that we can build a number of specifically archaeological elements into the presentation. So, for example, it means that we can set up a front end, so that when users come in they can be taken quite quickly to, for example, all of the articles about Roman archaeology using an archaeological classification or an archaeological subject index rather than the standard, generic keyword-type approach - which is fine as far as it goes, but by taking a specifically archaeological approach we can develop more specialised user tools to make it more accessible to people.

There is still quite a lot of work to be done. Broadly, we've now agreed most of the key underlying principles that will support the way we're going to take it forward. We're just putting in place all of the various legal documents that are required. We hope that we will be able to get the investment income from a variety of archaeological organisations by the end of this year. Then what we hope to do is have some sort of pilot system up and running by spring 2005, kick-starting the marketing campaign that will underpin what we need to do, and then, as I say, hopefully go live on $1^{\text {st }}$ January 2006.

Publications aside, what do you feel are the most useful and important roles for the internet within archaeology, and how do you think this may develop in the future?

That's a very good question. As a subject that deals with a lot of data, computer and technology tools are critical to us as basic research equipment. They underpin and facilitate nearly everything we do, not just the publication but right the way through: excavation, data collection, recording on site, and increasingly that is all being done digitally. The use of that technology has changed the way we work. Even with the most basic things like email, there are now different modes of working because people expect instant responses. If you sent somebody a letter 20 or 30 years ago, you thought you might get a response in two or three weeks, and that was perfectly acceptable. Now, when you send somebody an email, if they haven't replied within a day you wonder if they received it. It has had an impact on our working culture. There are bad things to that as well as good things. The most important thing from all of our points 
of view is the fact that it enables us now, from our desktops, to get access to a range of information that we previously would have struggled to find. The technology is there, and hopefully we can use it to generate new knowledge and contribute to our archaeological research.

One of the really interesting developments, I think, is the use of more personalised approaches to internet technology through things like web portals. One of the initiatives that we have been involved with is called HEIRNET, which is the Historic Environment Information Resources Network, which has established a portal that allows users to go into one website, on one webpage, and actually be able to cross-search a number of different archaeological databases. They can select which ones they want to search and which ones they don't want to search. This can be done through a map-based view; it can be done through a simple drop-down menu; and it can be done through simple keywords. They can then start to personalise what they see and how things come back - tailored to their particular interests - and that technology will develop significantly over the next few years. What will become commonplace within the next couple of years, is that your personal web browser will draw information from a number of possible sources. They will be personalised to your particular interests and there will be a lot more sharing - what is called 'syndicating' - of content, and that means that people will be able to get access more rapidly to the information which relates to their interests. It also means that they can start to use it and be kept up-to-date much more effectively. That is going to have quite an impact on the way we work.

These tools are being developed now; some of them exist already, and people are starting to incorporate them into their services. It also has implications for the way we operate as archaeologists. I went to a meeting recently about virtual reference collections for archaeology at a European level. We all rely to a large extent on reference collections for our work: as a zooarchaeologist you need to have comparative material to look at. Using the virtual technology that now exists, this information could be put together in a way that people could access it from their desktop, whether it is to do with Danish, Irish or British archaeology for example. The key thing is that people are going to be more collaborative in the way that they work on those sorts of initiatives, I think. And that will have big implications for the way that we work in our daily lives as archaeologists. I think that is going to be one of the biggest changes over the next few years. Beyond that - who knows?

\section{What do you think the role of television should be in archaeology and edu- cation about the past?}

Very broadly, I think that television is there to be entertaining and educational, and there are ways in which archaeology is the perfect subject for that. I think that's why so many people watch so many archaeology programmes on television. There is a general thirst for knowledge; people are inquisitive; people like the fact that this is about them, where they've come from and their sense of place, and there are really good opportunities to put that across through television and other media as well. I don't think we should forget radio - there are a lot of very good archaeology programmes on the radio, 
although sometimes it is more difficult to describe what you're seeing. Describing an archaeological section on the radio is a challenge I can assure you! I think archaeology, potentially, has everything to make good television programmes. The challenge is to make them in a way that focuses on the knowledge and the education, as well as the entertainment, and not the other way around.

What I think has been a very good development in the last few years is the introduction of a specific course at Bristol University linking together media and archaeology and starting to train archaeology graduates how to use the media technology and the ethos that underpins that to present what we do. I think that can only have a beneficial, longterm impact. Programmes like Restoration, for example, put across good messages about the value of buildings, about how they can be used, about how they fit within the landscape and the history of the place.

\section{How do you think collaboration can be improved between metal detector- ists and amateur archaeologists, and more professional field and museum staff?}

I think that is a very important agenda for the next few years. I think there has been a general alienation, certainly a perception of alienation, amongst the amateur community over the last few years, which is very sad. I hope that is something that we can work to improve and change. The CBA had a working group looking at the whole issue of public participation in archaeology, by which we mean active engagement in archaeology. That reported last year, so we are just at the moment considering how to take that forward. There are a number of major initiatives that we're talking about linked to some television opportunities that might be coming up in the next couple of years. I think that is an area where we certainly want to focus a lot of our efforts as an organisation.

There is a much better collaboration now with detectorists, mostly as a result of the Portable Antiquities Scheme, where there are now people on the ground whom detectorists can talk to and show the material they are finding. That is part of a broader educational agenda. The important thing is to emphasise continually that it is about knowledge - it is not about monetary value. It also means that we can start to get across other important archaeological messages about the value of context. For example, it is not the value of the object itself that matters; it is often where it came from and what it was associated with - these are very important messages that we need to convey. If you take a broad look over the last 20 or 30 years, we've done a lot better in the last few years in working collaboratively with different sectors of the community. But there is a long way to go. There are problems on all sides. There is still a small minority of metal detectorists who operate outside the law and who destroy archaeological sites, often at night, for commercial gain. What is an encouraging position nowadays, is that those people are condemned as much by other metal detectorists as they are by the archaeologists.

At the same time, professional archaeologists have become a bit obsessed by process and the way that archaeology is done, rather than why they are doing it, partly as a 
result of the work that has come through from PPG 16 [Planning Policy Guidance 16 - ed.] type archaeology in England and its equivalents in other parts of the UK. Often, the really interesting archaeology doesn't happen now because the developer is the client, and the developer is controlling the work to a certain extent. The classic example is if you are excavating a site, and because of the building technique that is being used, you only have to excavate down to a metre and a half, and although you know that there are some really important Viking, Roman or prehistoric deposits at two metres, you often can't go that far. What has happened as a result is that professional archaeologists have become clients of the developer, rather than seekers of knowledge.

What I think is interesting is that over the last few years there has been a significant rise in the number of community archaeology groups who are often interested local people who want to find out more about the past of their area. They are coming at it from the knowledge angle, not the process angle. In places like York there are some flourishing community archaeology projects based on particular parishes. The role of the professional archaeologists in those particular situations is to support and facilitate that work - not in a top-down mode, but actually to facilitate and encourage a bottomup type approach. That, again, is a different way of working and something that we need to become more comfortable with. It comes back to this issue about the Valetta Convention, and often the perspective of professional archaeologists is that they need to control the work of volunteers and amateur archaeologists. I think there is room for all sides, and we need to understand that archaeology is a public-interest subject. The fact that we can engage, facilitate and support community-based work is not something that many other disciplines have. The example that Mick Aston always quotes is that you wouldn't get a Young Accountants' Club. It is almost an amusing concept! Yet we have a Young Archaeologists' Club which has several thousand members. Those are real strengths for our discipline, and we need to make the best advantage of them and not alienate people.

\section{Finally, looking forward, what would you like to have remembered as your legacy to archaeology?}

It is one of those questions where I still feel I'm too young to answer! I suppose the obvious answer, given that I am now the director of the CBA, is that I will be able to make the CBA a very effective organisation for the benefit of all people interested in archaeology and the historic environment in this country, and not just for any one particular sector, professionals or amateurs or whoever. I hope that through that, we can also develop and maintain a large public supporters' club for our subject which will then go on to persuade the politicians that what we are doing is valuable and should be supported and resourced appropriately. That is the big agenda for the next few years, it seems to me. We need to get politicians of all parties and all persuasions at national, regional and local levels to understand that what we're doing contributes to all different aspects of society. It contributes economically, it contributes culturally, it contributes socially, it contributes educationally, and there are lots of real opportunities to take forward all sorts of government agendas through archaeology. If we can get that message across, then that will be a fantastic thing to be remembered for. Ask me again in about 20 years! 